\title{
A genotypic mutation system measuring mutations in restriction recognition sequences
}

\author{
Emanuela Felley-Bosco, Charareh Pourzand, Jacob Zijlstra ${ }^{+}$, Paul Amstad and Peter Cerutti ${ }^{*}$ \\ Department of Carcinogenesis, Swiss Institute for Experimental Cancer Research, \\ 1066 Epalinges/Lausanne, Switzerland
}

Received March 7, 1991; Revised and Accepted May 15, 1991

\begin{abstract}
The RFLP/PCR approach (restriction fragment length polymorphism/polymerase chain reaction) to genotypic mutation analysis described here measures mutations in restriction recognition sequences. Wild-type DNA is restricted before the resistant, mutated sequences are amplified by PCR and cloned. We tested the capacity of this experimental design to isolate a few copies of a mutated sequence of the human c-Ha-ras1 gene from a large excess of wild-type DNA. For this purpose we constructed a 272 bp fragment with 2 mutations in the Pvull recognition sequence 1727-1732 and studied the rescue by RFLP/PCR of a few copies of this 'Pvull mutant standard'. Following amplification with Taqpolymerase and cloning into $\lambda$ gt 10 , plaques containing wild-type sequence, Pvull mutant standard or Taqpolymerase induced bp changes were quantitated by hybridization with specific oligonucleotide probes. Our results indicate that 10 Pvull mutant standard copies can be rescued from $10^{8}$ to $10^{9}$ wild-type sequences. Taq polymerase errors originating from unrestricted, residual wild-type DNA were sequence dependent and consisted mostly of transversions originating at G.C bp. In contrast to a doubly mutated 'standard' the capacity to rescue single bp mutations by RFLP/PCR is limited by Taq-polymerase errors. Therefore, we assessed the capacity of our protocol to isolate a $\mathbf{G}$ to $\mathrm{T}$ transversion mutation at base pair 1698 of the Mspl-site 1695-1698 of the c-Ha-ras1 gene from excess wild-type ras1 DNA. We found that 100 copies of the mutated ras 1 fragment could be readily rescued from $10^{8}$ copies of wild-type DNA.
\end{abstract}

\section{INTRODUCTION}

Molecular characterization and quantitation of mutations is of fundamental importance to the understanding of evolution, differentiation and the etiology of hereditary disease. The frequent occurrence of single base pair changes in the activation of the ras protooncogenes (1) and in the inactivation of the tumor suppressor gene p53 (2-4) documents the involvement of mutations in human carcinogenesis. Ideally, methods are required which allow it to identify specific DNA sequence changes in relevant genes in tissue biopsies. For the elucidation of early pathogenetic processes it is necessary to detect these changes in a minute minority of cells without the clonal expansion of mutated cells in vivo or in vitro and without the need for the expression of a selectable mutant phenotype (5). To achieve this goal it is necessary to isolate specific mutated DNA sequences from a large excess of homologous wild type DNA by biochemical means. In contrast, all classical 'phenotypic' mutation systems rely on the isolation of a few mutated cells from a large, usually dividing cell population. This limits mutation analysis to a few genes encoding proteins which produce a selectable cellular phenotype.

A number of experimental approaches to 'genotypic' mutation systems have been developed (6). Several are based on Southernor Northern hybridization often with sequence amplification by polymerase chain reaction (PCR) and in combination with the specific cleavage of hetero-duplexes at mismatched base pairs. Other protocols take advantage of differences in electrophoretic mobilities of hetero-duplexes or of mutated single stranded nucleic acids. The sensitivity of all these approaches are limited by backgrounds which arise from the presence of excess wild-type sequences. The RFLP/PCR approach to genotypic mutation analysis described here greatly reduces this problem. Base-pair (bp) mutations are detected which are located in a restriction recognition sequence and render this site resistant to cleavage by the corresponding endonuclease. The resistant DNA sequence containing the mutated site is amplified by PCR only after wild type DNA has been essentially eliminated by restriction digestion. Amplified DNA is cloned into $\lambda$ gt10 and mutants are quantitated by oligonucleotide plaque hybridization relative to an internal standard. The maximal sensitivity of the RFLP/PCR method is determined by the completeness of the removal of wild-type sequences together with the inherent error-rate at a particular base pair of the polymerase used in the PCR. The RFLP/PCR protocol for genotypic mutation analysis is applicable to any gene of known sequence. It is highly sensitive, but limited to the identification of point mutations (bp-changes, small deletions and insertions)

\footnotetext{
* To whom correspondence should be addressed

+ Present address: Toxicology Department-ZYMA SA-1260 Nyon, Switzerland
} 
which result in the elimination of restriction sites. We report here results involving bp-changes in the PvuII site 1727-1732 and the MspI site 1695-1698 of exon 1 of the human c-Ha-ras1 gene. The MspI-site $1695-1698$ covers 2 bp of codon 12 of c-ras which represents a mutation hot spot in human cancer (1).

\section{METHODS}

\section{RFLP/PCR analysis of PvulI-site 1727-1732 of c-Ha-ras1}

Preparation of authentic mutants at PvulI-site 1727-1732 of cHa-rasl. All 12 possible single bp mutations in the internal tetranucleotide AGCT of the PvuII recognition sequence (residues 1727-1732) of exon 1 of the human c-Ha-ras1 gene were prepared using synthetic oligonuleotides and a PCR protocol (see Figure 1 for sequence information). Twelve different 20-mers corresponding to residues $1719-1738$ which contained single base changes in the AGCT sequence were used as left-side amplimers. A common right-side amplimer corresponding to nucleotides $1765-1784$ of $\mathrm{c}-\mathrm{Ha}$-rasl plus a 12 nucleotide tail containing an EcoRI recognition-sequence was used in 12 PCR reactions with pSVneo-ras1 as template (note: pSVneo-ras 1 contains the BamHI fragment, residues 1-6453, of human cHa-ras1 (7) inserted into the BamHI sites of the SVneo cloning vector). The amplification conditions were as described below. The 12 resulting 78 bp fragments were purified on Quiagen-5 tips as described by the supplier (DIAGEN, KONTRON, Switzerland) and then used as right-side amplimers in a second round of amplifications with a common left-side amplimer corresponding to residues $1646-1665$ of $\mathrm{c}-\mathrm{Ha}$-ras 1 plus a 12 nucleotide tail containing an EcoRI recognition sequence. The resulting $163 \mathrm{bp}$ fragments were purified on Quiagen-5 tips, digested with EcoRI and cloned into $\lambda \mathrm{gt} 10$.

All authentic mutant $\lambda \mathrm{gt} 10$ constructs were plaque purified on E. coli $\mathrm{C} 600 \mathrm{Hfl}$. For this purpose plaques were lifted onto colony/plaque screens and probed with mutant specific ${ }^{32} \mathrm{P}$-endlabeled oligonucleotides. Positive plaques were picked, the phage eluted from the agar and plated onto E. coli C600 Hfl. When confluent lysis had been achieved the phage was collected in $5 \mathrm{ml}$ buffer $(100 \mathrm{mM} \mathrm{NaCl}, 20 \mathrm{mM}$ Tris. $\mathrm{HCl} \mathrm{pH} \mathrm{7.4,} 10 \mathrm{mM}$ $\mathrm{MgSO}_{4}$ ) and after the addition of $100 \mu \mathrm{l} \mathrm{CHCl}_{3}$ the suspension was centrifuged at $10^{\prime} 000 \mathrm{rpm}$ for $10 \mathrm{~min}$ at $4^{\circ} \mathrm{C}$. Mutant phage contained in the supernatant was titered and then stored at $4^{\circ} \mathrm{C}$ in the presence of $0.3 \% \mathrm{CHCl}_{3}$.

A mutant standard with two bp changes in the PvuII recognition sequence and an additional upstream mutation was prepared according to the same experimental design using the 20-mer 5' $\mathrm{T}$ GAGCATCCTGGTGATCCAG (residues 1719-1738 of c-Haras1; positions of mutations underlined) as left-side amplimer and a 20 -mer corresponding to the sequence from residue 1888 to 1907 of c-Ha-ras 1 as right-side amplimer. The right-side amplimer contains a Xbal recognition site. The amplification conditions were as described below except that the DMSO concentration was only $6 \%$. After 38 cycles the resulting 188 bp fragment was purified on a Quiagen-5 tip and used as rightside amplimer in a second amplification reaction with a left-side amplimer corresponding to residues 1636 to 1655 of c-Ha-ras 1 which contains a SmaI site. After purification the final $272 \mathrm{bp}$ fragment was digested with $\mathrm{XbaI}$ and SmaI and cloned into pSP64. This plasmid, referred to as 'mutant standard' (pSP64-ras PvuIISt), was used as internal standard in mixtures with pSVneo-ras1.
PvII - restriction and amplification . A stock of pSVneo-ras1 was digested exhaustively with $4 \mathrm{U}$ PvuII $/ \mu \mathrm{g}$ plasmid DNA in Tris buffer $\mathrm{pH} 7.5,10 \mathrm{mM} \mathrm{MgCl} 2,50 \mathrm{mM} \mathrm{NaCl}, 1 \mathrm{mM}$ DTE for 3 $\mathrm{h}$ at $37^{\circ} \mathrm{C}$. To $10^{8}$ copies of restricted pSVneo-ras1 was added 10 or 100 copies of PvulI mutant standard (see above) which had been predigested with $\mathrm{XbaI}$ and $\mathrm{SmaI}$ in order to release a $272 \mathrm{bp}$ fragment containing the mutated sequence. The samples were prepared in the amplification buffer which was composed of $66.7 \mathrm{mM}$ Tris. $\mathrm{HCl} \mathrm{pH} 8.8\left(25^{\circ} \mathrm{C}\right), 6.7 \mathrm{mM} \mathrm{MgCl}_{2}, 16.6 \mathrm{mM}$ $\left(\mathrm{NH}_{4}\right)_{2} \mathrm{SO}_{4}, 1 \mathrm{mM}$ each of the $4 \mathrm{dNTPs}, 12 \%$ DMSO, $1.25 \mu \mathrm{M}$ of the left-side and right-side amplimers in a final volume of 25 $\mu \mathrm{l}$. The amplimers used in the first 30 PCR cycles were 20 -mers corresponding to the sequences $1646-1665$ and $1765-1784$ of c-Ha-ras1 (see Figure 1). After addition of $0.5 \mathrm{U}$ of Taq polymerase (from bact. Thermus aquaticus, Cetus, Calif.) the samples were heated initially to $91^{\circ} \mathrm{C}$ for 4 min followed by 95 $\mathrm{sec}$ at $59^{\circ} \mathrm{C}$. Consecutive cycles consisted of $85 \mathrm{sec}$ at $91^{\circ} \mathrm{C}$ and $95 \mathrm{sec}$ at $59^{\circ} \mathrm{C}$ and were carried out in an Ampligene Apparatus, Moretronic, Switzerland. After 2,4,6 and 8 cycles 1 U PvuII was added and the samples incubated for $10 \mathrm{~min}$ at $52^{\circ} \mathrm{C}$ in order to eliminate any amplified wt-sequence. Amplification was then continued with $0.5 \mathrm{U}$ fresh Taq-polymerase. After the first 8 cycles the amplification was continued without interruption up to 30 cycles when a $1 \mu \mathrm{l}$ aliquot was withdrawn from each sample and added to $50 \mu \mathrm{l}$ fresh amplification buffer. The mixtures contained $1.6 \mu \mathrm{M}$ of clonable amplimers which in addition to the 20-mer sequences described above contained a 12-nucleotide tail with an EcoRI-recognition sequence (see Figure 1). Before the continuation of the amplification for 10 cycles the samples were treated with PvuII for $20 \mathrm{~min}$ at $37^{\circ} \mathrm{C}$. In independent experiments $10^{9}$ copies of PvuII digested pSVneo-ras1 were mixed with 1 or 1000 copies of mutant standard and processed according to the protocol described above except that PvuII digestions during amplification were omitted.

Purification of amplified DNA and cloning into $\lambda$ gt10. The amplification mixtures were purified on Quiagen-5 tips and the DNA precipitated with isopropanol after the addition of $1 \mu \mathrm{g} \mathrm{E}$. coli tRNA as carrier. The samples were then treated with EcoRI in order to free the ends of the amplified fragment. After renewed purification on Quiagen-5 tips, precipitation with isopropanol and washing of the precipitates with $75 \%$ ethanol 5ng/DNA aliquots were ligated to $500 \mathrm{ng} \lambda \mathrm{gt} 10 \mathrm{arms}$ as outlined by the supplier (Promega Biotec, Madison, WI.) The phage DNA was packaged (Packagener, Promega Biotec, Madison, WI.) and E. coli C600 $\mathrm{Hfl}$ infected. Plaques were lifted onto colony/plaque screens (NEF-978, New England Nuclear). At least 2 independent packagings were carried out and $1-3 \times 10^{3}$ plaques on 10 to 15 Petri-dishes were analyzed for each experimental condition.

Oligonucleotide plaque hybridization. Specific probes were prepared according to standard conditions by end-labeling with gamma- ${ }^{32} \mathrm{P}-\mathrm{ATP}$ with T4 polynucleotide kinase of oligonucleotide 20 -mers corresponding to the wild-type sequence 1719-1738 of c-Ha-ras1, mutant standard containing 3 base changes and oligomers containing all 12 possible single base mutations in the internal tetranucleotide AGCT of PvuII recognition site $1727-1732$. The colony/plaque screens to be analyzed were prehybridized for $1 \mathrm{~h}$ with $5 \times$ SSPE $(1 \times: 10 \mathrm{mM}$ Na-phosphate pH 7.4, 1mM EDTA, $0.15 \mathrm{M} \mathrm{NaCl}$ ), 0.3\% SDS, $1 \%$ milk protein. After rinsing with water the discs were hybridized overnight with the radioactive probes at $54^{\circ} \mathrm{C}$ in 
$5 \times$ SSPE, $0.3 \%$ SDS. After a first wash at room-temperature with $5 \times$ SSPE selective washing temperatures between 60 and $63^{\circ} \mathrm{C}$ were employed in order to exclude non-specific hybridization. The selective washing temperatures were determined with known mixtures of $\lambda$ gt 10 stocks containing authentic mutant inserts (for their preparation see above).

\section{RFLP/PCR analysis of MspI-site 1695-1698 of c-Ha-ras1}

Preparation of authentic mutant ras1-T1698 with a single base pair substitution in the MspI-site 1695-1698. The c-Ha-ras1 gene with a $G \rightarrow T$ transversion at residue 1698 of exon 1 had been originally cloned from the EJ human bladder carcinoma line (8). A Smal fragment (1644-2246) of this gene was cloned into the vector puc 8. From this the XbaI-EcoRI ras fragment 1644-1905 was removed and cloned into the pSP64 vector (9). This vector, referred to below as pSP64-ras1-T1698 was used in the mutant rescue experiments described below.

MspI/HpaII-restriction and amplification. Stocks of pSVneo-ras1 were digested exhaustively with $10 \mathrm{U} \mathrm{MspI/ \mu g}$ and $2 \mathrm{U} \mathrm{Hpall} / \mathrm{ug}$ plasmid overnight at $37^{\circ}$ under the conditions described above for PvuII. pSP64-ras1-T1698 was digested with XbaI-EcoRI in order to release a $261 \mathrm{bp}$ fragment containing the mutated MspIsite 1695-1698 CCGT. Three samples were prepared in the amplification buffer described above except that the DMSO concentration was only $6 \%$ : a) $10^{8}$ copies restricted pSVneoras 1 b) 100 copies restricted pSP64-ras1-T1698 plus $10^{8}$ copies restricted pSVneo-ras 1 c) 1000 copies restricted pSP64-ras1-T1698 plus $10^{8}$ copies restricted pSVneo-ras1. The amplimers used in the first 35 PCR cycles were 20-mers corresponding to the sequences $1646-1665$ and $1765-1784$ of c-Ha-ras1 (see Figure 1). The amplification cycles were as described above. After $2,4,6,8,10,12$ and 14 cycles $2 U$ MspI were added and the samples incubated for $10 \mathrm{~min}$ at $55^{\circ}$ in order to eliminate any residual wild-type sequences. Amplification was then continued after the addition of $0.5 \mathrm{U}$ fresh Taq polymerase. After 14 cycles the amplification was continued to 35 cycles without interruption when a $1 \mu l$ aliquot was withdrawn from each

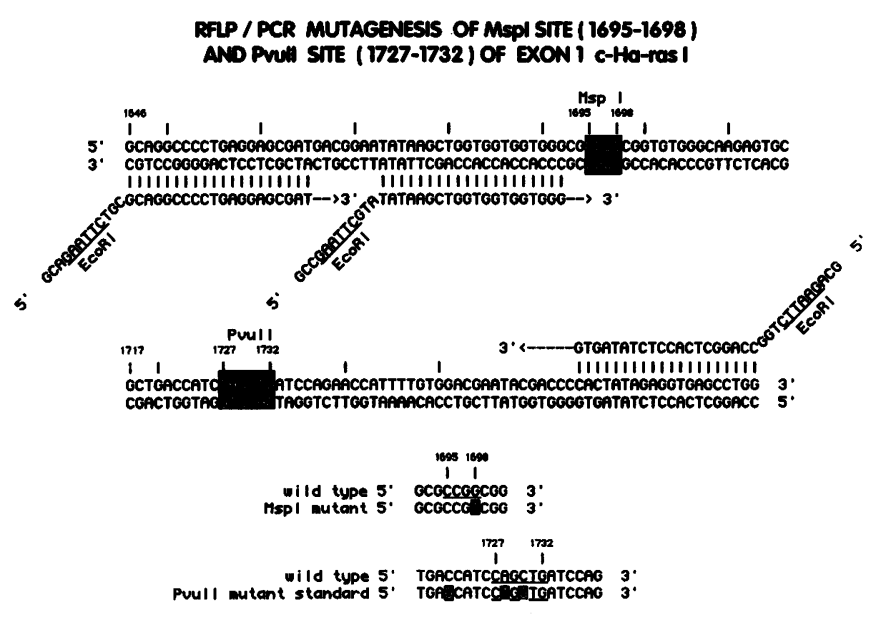

Figure 1. Sequence 1646-1784 of exon 1 of human c-Ha-ras1. The MspI recognition site $1695-1698$ and the PvuII recognition site $1727-1732$ used in the RFLP/PCR experiments are marked. The sequences of the single base pair mutant pSP64-ras1-T1698 in the MspI-site 1695-1698 and of the Pvull mutant standard SP64-ras-PvuIISt are given in the lower part of the Figure. Only the sequences of the 'clonable' amplimers with 5'-tails containing EcoRI recognition sites are shown. sample and added to $50 \mu \mathrm{l}$ fresh amplification buffer. The amplification was continued with $1.6 \mu \mathrm{M}$ nested clonable left-side amplimer 1673-1692 and clonable right-side amplimer 1765-1784. These amplimers possessed 12-nucleotide 5'-tails containing EcoRI-recognition sequences (see Figure 1). All subsequent steps consisting of purification of the amplified DNA, cloning into $\lambda \mathrm{gt} 10$ and oligonucleotide plaque hybridization were as described above for the analysis of mutants in the Pvull-site 1727-1732. The results shown on Figure 5 are derived from 2 independent packagings and $600-1100$ plaques on 4 to 6 Petri dishes.

\section{Radiolabeled amplimer incorporation}

In order to compare the efficiency of amplification of mutant standard and wild-type c-Ha-ras1 DNA the 20-mer corresponding to residues $1646-1665$ was end-labeled with $\gamma-32$ P-ATP and T4 polynucleotide kinase under standard conditions. This

A
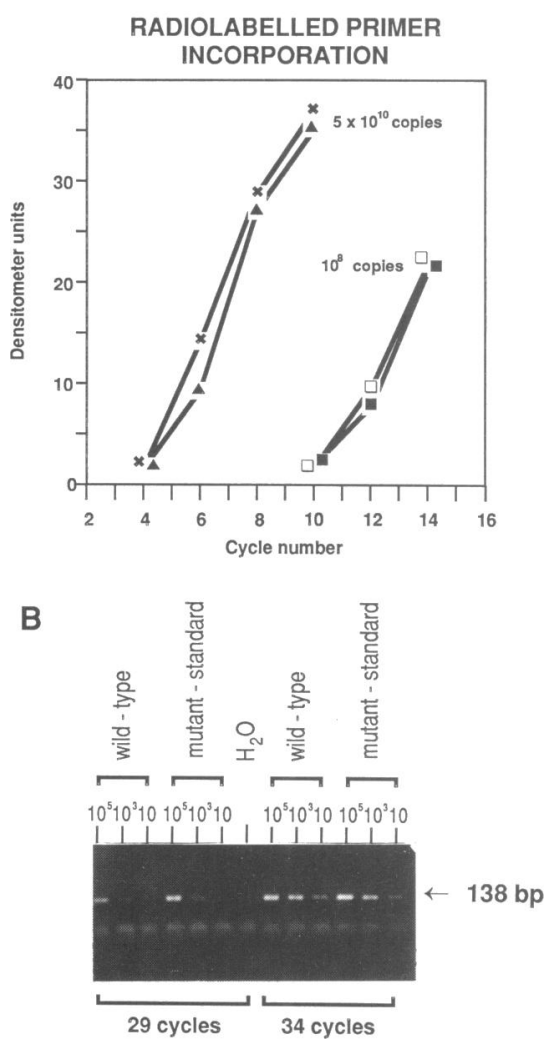

Figure 2. Comparison of amplification efficiencies of the wild-type c-Ha-ras1 sequence 1646-1784 and of the corresponding PvII mutant standard sequence. A. Incorporation of $5^{\prime}-{ }^{32} \mathrm{P}$-endlabeled left-side amplimer into $138 \mathrm{bp}$ amplified fragment with Taq-polymerase. Aliquots were withdrawn at increasing numbers of PCR-cycles and applied on 5\% polyacrylamide gels for electrophoretic analysis. The dried gels were exposed to $x$-ray film for autoradiography and the intensity of the bands at $138 \mathrm{bp}$ determined by densitometry. X-X and $\square-\square, 5 \times 10^{10}$ and $10^{8}$ copies of $\mathrm{XbaI} / \mathrm{Smal}$ digested wild-type $\mathrm{pSVneo-ras}$ were used as template, respectively; $\Delta-\Delta$ and $-\square, 5 \times 10^{10}$ and $10^{8}$ copies of $\mathrm{Xbal} / \mathrm{Smal}$ digested mutant standard pSP64-ras PvuIISt were used as template, respectively (see 'Methods'). B. Formation of 138bp sequence $1646-1784$ by amplification with Taq-polymerase of $10^{5}, 10^{3}$ and 10 copies of $\mathrm{XbaI} / \mathrm{SmaI}$-digested wild-type pSVneo-ras or mutant standard pSP64-ras PvuIISt as templates. After the indicated numbers of PCR-cycles aliquots of the reaction mixtures were electrophoresed on $2 \%$ agarose gels and the $138 \mathrm{bp}$ band visualized by ethidiumbromide staining (see 'Methods'). 
radiolabeled oligonucleotide was used as left-side amplimer in a PCR-reaction with a non-radioactive right-side amplimer and $5 \times 10^{10}$ copies of $\mathrm{XbaI}$ and SmaI digested mutant standard pSP64-ras PvuIISt or of XbaI and SmaI digested pSVneo-ras1 as templates, respectively. In a second experiment only $10^{8}$ copies of the template DNAs were used. Amplification conditions were as described above with the exception that no PvuII digestions were performed. Aliquots of the reaction mixtures were withdrawn after increasing numbers of PCR cycles and applied to $5 \%$ polyacrylamide gels. After development, the dried gels were exposed to $\mathrm{x}$-ray film for autoradiography. The intensities of the bands at $138 \mathrm{bp}$ corresponding to the expected amplification product were determined by densitometry (Zeineth Scanning densitometer, Biomed Instr., CA.).

\section{RESULTS}

Efficiency of amplification of PvuII mutant standard and wild-type sequence 1646-1784 of c-Ha-ras1

In order to calibrate single bp mutations by RFLP/PCR an internal 'Pvull mutant standard' is used with 2 bp-mutations in the chosen recognition sequence. We prepared a mutant standard pSP64-ras PvuIISt with 2 bp changes in the PvuII recognition sequence (1727-1732) and an additional mutation upstream (see Methods and Fig. 1). For the validity of the calibration the amplification efficiencies for mutant standard DNA and mutated sequences (or undigested wt-sequences) from genomic DNA have to be the same. This is demonstrated in Figure 2. The upper portion shows that radiolabeled left-side amplimer (see Figure 1 for sequences) was incorporated into the desired $138 \mathrm{bp}$ fragment with equal efficiency whether mutant standard or wt-sequence served as template. Either $5 \times 10^{10}$ or $10^{8}$ initial copies of the templates were amplified for 10 or 14 PCR cycles, respectively. The lower portion of Figure 2 compares the amounts of $138 \mathrm{bp}$ fragment synthesized from $10^{5}, 10^{3}$ and 10 copies of the two templates after 29 and 34 PCR cycles directly by ethidiumbromide staining on a $2 \%$ agarose gel. The results indicate comparable amplification efficiencies for PvuII mutant standard- and wttemplate also at low numbers of initial copies and high cycle numbers.

\section{Rescue of PvulI mutant standard from excess wild-type sequence $1646-1784$ of $\mathrm{c}$-Ha-ras1}

The capability of the RFLP/PCR method to rescue a small number of copies of PvulI mutant standard from a large excess of wt sequence was investigated. Mixtures were prepared of 10 and 100 copies of $\mathrm{XbaI} / \mathrm{SmaI}$ digested mutant standard pSP64-ras PvuIISt with $10^{8}$ copies of exhaustively PvuII digested pSVneoras 1 and of 1000 copies of mutant standard with $10^{9}$ copies PvuII digested pSVneo-ras 1 . The mutant standard was restricted with XbaI/SmaI in order to release a 272 bp fragment similar in size to the 256 bp ras-fragment which is liberated by PvuII from pSVneo-ras 1 containing a mutation in the PvuII site 1727-1732. The mixtures were amplified with repeated restrictions with PvuII in 30 cycles with 'non-clonable' amplimers and 10 final cycles with amplimers containing tails with EcoRI recognition sequences (see 'Methods' and Figure 1). The 163bp amplified fragments were cloned into $\lambda \mathrm{gt} 10$ and plaques were analyzed by oligonucleotide hybridization for their content in wt ras1 sequence 1719-1738 and mutant standard sequence.

The results summarized in Table 1 show that as few as 10 copies of PvuII mutant standard were rescued from $10^{8}$ copies

\section{ANALYSIS OF AMPLIFICATION MIXTURE BY $\lambda$-PLAQUE HYBRIDIZATION *}

\begin{tabular}{|c|c|c|c|}
\hline Mutant standard & Wild type & $\begin{array}{c}\text { Mutant standard } \\
\% \text { plaques }\end{array}$ & $\begin{array}{c}\text { Wild type } \\
\% \text { plaques }\end{array}$ \\
\hline 10 & $10^{8}$ & $7.3 \pm 0.8$ & $23.3 \pm 1.2$ \\
100 & $10^{8}$ & $13.9 \pm 1.3$ & $14.3 \pm 1.4$ \\
\hline 1000 & $10^{9}$ & $18.0 \pm 1.7$ & $20.4 \pm 1.7$ \\
\hline
\end{tabular}

- Plaques containing mutant standard or wild-type sequence at the Pvull recognition sequence ( $\# 1727$ - 1732) Phage from at least 2 packagings were used and plaques on 10-15 petri dishes were analysed.

CAGCTG wild - type
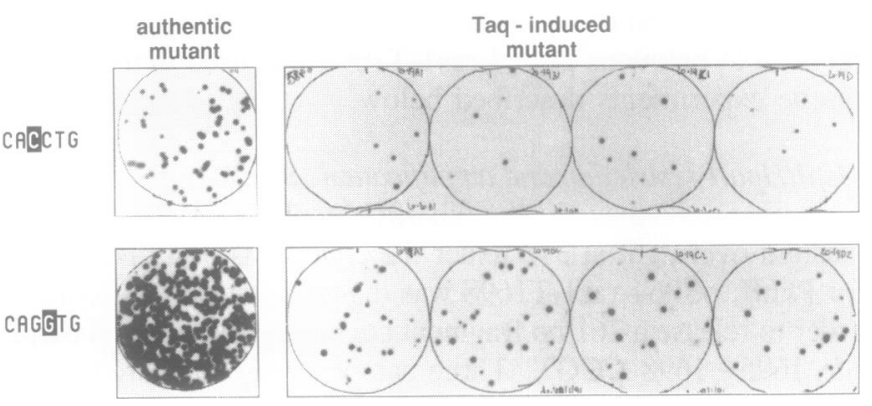

Figure 3. Analysis of $\lambda$-plaques for base-pair mutations in Pvull-recognition sequence $1727-1732$ of c-Ha-ras 1. Mixtures of a few copies of mutant standard pSP64-ras PvuIISt with $10^{8}$ copies of wild-type pSVneo-ras were processed by the RFLP/PCR protocol described in 'Methods'. The amplification product was cloned into $\lambda$ gt 10 , plaques transferred to plaque screens and analyzed by hybridization with ${ }^{32}$-P-end-labeled mutant oligonucleotide probes for Taqpolymerase induced single bp mutations in the PvuII recognition sequence 1727-1732. The selectivity of the washing conditions was ascertained for each mutation with authentic mutant constructs. Upper half, left-side: plaques containing authentic mutant CACCTG; right-side: plaques on 4 plates with same mutation originating from the amplification mixture. Lower half, left-side: plaques containing authentic mutant CAGGTG; right-side: plaques on 4 plates with the same mutation originating from the amplification mixture.

of wt-sequence giving rise to $7.3 \%$ of total plaques. Increasing initial copy numbers of PvulI mutant standard gave rise to larger fractions of plaques containing the mutant standard sequence. The fractions of wt-plaques varied from 14 to $23 \%$.

\section{Taq-polymerase errors in PvuII-site 1727-1732 of c-Ha-ras1}

Despite exhaustive restriction with PvuII before and during amplification a small amount of intact wt-sequences undoubtedly remains, will be amplified and can give rise to Taq-polymerase errors. Amplified sequences containing Taq-polymerase errors in the PvuII recognition sequence $1727-1732$ are resistant to digestion and will be cloned. The ultimate sensitivity of the RFLP/PCR method for a particular bp in the chosen recognition site depends on the error-rate of Taq-polymerase for the replication of this bp. Therefore, we probed $\lambda$-plaques resulting from the mixtures of mutant standard with excess wt-sequence for their content of Taq-polymerase induced single bp changes in the internal tetranucleotide AGCT of the PvuII recognition sequence. The plaques were probed with specific oligonucleotides for all 12 possible mutations. Figure 3 shows an example in which discs had been probed for a $\mathrm{G} \rightarrow \mathrm{C}$ transversion giving rise to 
1 copy Pvu II mutant standard: TGGT $10^{9}$ copies wild - type : AGCT
10 copies Pvu II mutant standard: TGGT $10^{8}$ copies wild - type : AGCT
100 copies Pvu II mutant standard: TGGT

$10^{8}$ copies wild - type : AGCT
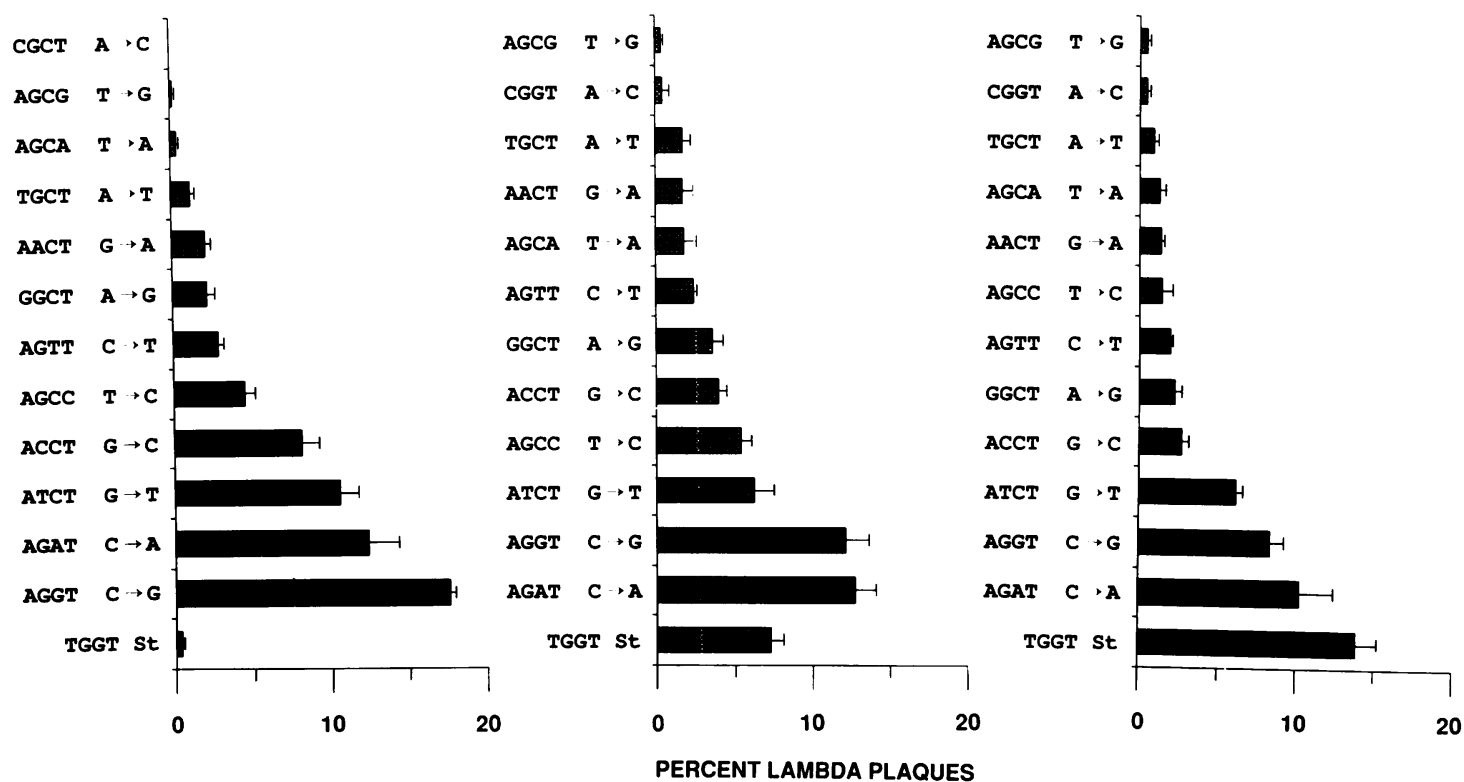

Figure 4. Spectrum of Taq-polymerase induced base-pair mutations in the PvuII-site 1727-1732 of exon 1 of c-Ha-ras1. Mixtures of a few copies of mutant standard pSP64-ras PvuIISt with $10^{8}$ or $10^{9}$ copies of wild-type pSVneo-ras were processed by the RFLP/PCR protocol as described in 'Methods'. $\lambda$-plaques were transferred onto plaque screens and analyzed for their content of all 12 possible bp mutations in the internal tetranucleotide AGCT of the Pvull- recognition sequence by hybridization with ${ }^{32}$-P-end-labeled oligonucleotide probes. The results represent means from two $\lambda$-packagings and $10-15$ petri dishes containing $100-200$ plaques for each experimental condition. The selectivity of the conditions for each probe was ascertained with authentic mutant constructs. Individual plaques only hybridized with a single probe (see 'Methods').

CACCTG occurring with moderate frequency (upper portion) and a $\mathrm{C} \rightarrow \mathrm{G}$ transversion giving rise to CAGGTG which represents a frequent Taq-induced mutation in the Pvull site (lower portion). In all cases the specificity of the probing conditions was ascertained with mixtures of authentic mutant constructs and by assuring that each plaque only hybridized with a single oligonucleotide probe.

Figure 4 compares the frequencies of the 12 possible Taqpolymerase induced bp changes at the internal tetranucleotide AGCT of the PvuII-site in 3 independent amplification experiments in which $10^{9}$ (Figure 4A) and $10^{8}$ initial copies of wt pSVneoras1 (Figure 4B \& C) were used, respectively. While there are small quantitative differences the following consensus can be reached for the relative abundance of Taq-induced errors: $\mathrm{C} \rightarrow \mathrm{A}(\mathrm{AG} \underline{\mathrm{AT}}) \cong \mathrm{C} \rightarrow \mathrm{G}(\mathrm{AGGT})>\mathrm{G} \rightarrow \mathrm{T}(\mathrm{A} \underline{\mathrm{TCT}})$. Since the amount of wt-copies which remain undigested during the amplification cycles is not known absolute Taq-error frequencies cannot be derived from our data. In contrast, from a comparison to the data with the mutant standard it is evident that less than 10 copies containing a single bp mutation in the presence of $10^{9}$ copies of wt-sequence can readily be detected for mutations with low Taq-error frequencies, e.g. for $A \rightarrow C(C G C T) ; T \rightarrow G(A-$ $\mathrm{GC} \underline{\mathrm{G}}) ; \mathrm{T} \rightarrow \mathrm{A}(\mathrm{AGC} \underline{\mathrm{A}}) ; \mathrm{A} \rightarrow \mathrm{T}(\mathrm{TGCT}) ; \mathrm{G} \rightarrow \mathrm{A}(\mathrm{A} \underline{\mathrm{ACT}})$.

Rescue of a single base pair mutation in MspI-site 1695-1698 from excess wild-type c-Ha-ras1 DNA

The rescue of mutant standard such as pSP64-ras PvulISt with multiple bp changes in a chosen restriction site from excess wt sequences is not affected by Taq-polymerase errors. In contrast, the sensitivity of the detection of single bp mutations is limited by polymerase errors originating from the amplification of residual undigested wt sequences. We assessed the capacity of the RFLP/PCR protocol to rescue a few copies of the c-Ha-ras1 exon 1 fragment $1646-1784$ containing a $G \rightarrow T$ transversion at residue 1698 which is part of the MspI-site 1695-1698 from a large excess of wt c-Ha-ras1 DNA. The chosen mutation affects the middle bp of codon 12 and was detected in the c-Ha-ras1 gene of the EJ human bladder carcinoma line (8) (see Figure 1 for sequence information). Three samples were analyzed by RFLP/PCR (1) $10^{8}$ copies of exhaustively MspI/Hpall digested wt pSVneo-ras1 (2) 100 copies mutant pSP64-ras1-T1698 (XbaI/EcoRI restricted) plus $10^{8}$ copies MspI/Hpall digested pSVneo-ras (3) 1000 copies mutant pSP64-ras1-T1698 (XbaI/EcoRI restricted) plus $10^{8}$ copies MspI/Hpall digested pSVneo-ras1. The samples were amplified with repeated MspI restrictions in 35 cycles with 'non-clonable' amplimers and 10 final cycles with amplimers containing tails with EcoRI recognition sequences (see Figure 1 and Methods). The amplified $136 \mathrm{bp}$ fragments were cloned into $\lambda \mathrm{gt} 10$ and plaques analyzed by hybridization with 20 -mer oligonucleotides corresponding to the wt c-Ha-ras1 sequence 1688-1707 and with the mutant sequence containing a T-residue at position 1698. From the results shown in Figure 5 it is evident that Taq-polymerase amplification of residual wt ras1 DNA which escaped restriction at the MspIsite 1695-1698 generated $12 \% \quad \lambda$-plaques with $G \rightarrow T$ transversions at residue 1698 for the sample containing only $10^{8}$ copies of pSVneo-ras 1 at the outset. The percentage of plaques containing $\mathrm{G} \rightarrow \mathrm{T}$ transversions at residue 1698 was $23 \%$ for the initial mixture of 100 copies mutant pSP64-ras1-T1698 with $10^{8}$ copies of wt pSVneo-ras1 corresponding to a 2 fold increase over 


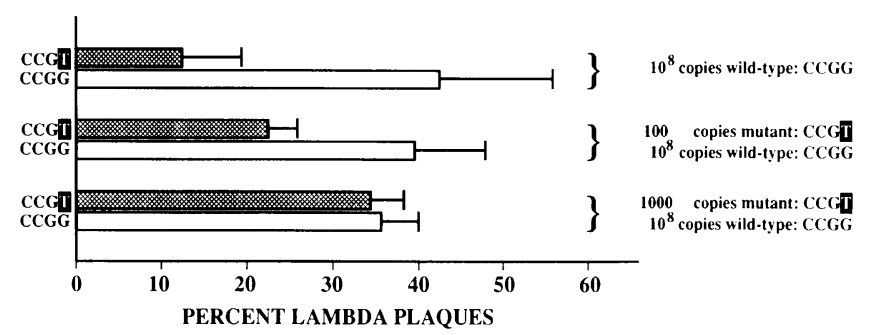

Figure 5. Rescue of a single base pair mutation in the MspI-site 1695-1698 of c-Ha-ras 1 from excess wild type DNA. Three samples of c-Ha-ras1 DNA were analyzed by the RFLP/PCR protocol for mutations in the MspI-site 1695-1698: (1) $10^{8}$ copies of exhaustively MspI/HpaII digested pSVneo-ras 1 (2) 100 copies of mutant pSP64-ras1-T1698 (xbaI/EcoRI digested) plus $10^{8}$ copies MspI/HpaII digested pSVneo-rasl (3) 1000 copies mutant pSP64-ras1-T1698 (XbaI/EcoRI digested)plus $10^{8}$ copies MspI/HpaII digested pSVneo-ras1. The conditions for amplification, cloning of the amplified fragments into $\lambda$ gt 10 and analysis of plaques by hybridization with ${ }^{32} \mathrm{P}$-end-labeled wt- and mutant (T1698) oligonucleotide probes are described under 'Methods'. Results are derived from 2 independent packagings and $600-1100$ plaques on $4-6$ Petri dishes. Error bars represent standard deviations.

the fraction produced by Taq-polymerase infidelity. At 1000 initial copies of mutant pSP64-ras1-T1698 plus $10^{8}$ copies wt $\mathrm{pSVneo-ras} 1$ the percentage of mutant plaques had increased to $34 \%$. The Figure also gives the percentage of plaques which contained wt-sequence $1688-1707$.

\section{DISCUSSION}

The aim of the present work was to test the feasibility to use the RFLP/PCR approach for the development of a genotypic mutation system. Such a system should be capable of measuring low frequency mutations in any gene of known sequence without the need for the phenotypic selection of mutated cells (6). In the RFLP/PCR approach wt-sequences are selectively removed by exhaustive restriction and resistant sequences are amplified by PCR. We have chosen the tetranucleotide AGCT of PvuII recognition site for our studies because it contains all 4 nucleotides. While the composition of the PCR product reflects the initial mixture of mutations it does not allow the estimation of absolute mutation frequencies. Therefore, we are using an internal 'mutant standard' for calibration. We have constructed a mutant standard with 2 bp changes in PvuII recognition site and a third mutation upstream. This allows the distinction between $\lambda$-plaques containing mutant standard from plaques containing single bp mutations in the final analysis with specific probes. In the present experiments we have used the mutant standard pSP64-ras PvuIISt to evaluate the capacity of the RFLP/PCR protocol to rescue a few copies of mutated sequences in the PvuII site 1727-1732 from a large excess of wt c-Ha-ras1 without interference by Taq-polymerase errors. We have ascertained that mutant standard and wt-sequences are amplified with equal efficiencies (see Figure 2). Our results indicate (Table 1) that 10 copies of mutant standard were readily rescued from $10^{8}$ to $10^{9}$ copies of wt-DNA. While the fraction of mutant standard plaques increased with increasing copy number there is no simple relationship between the two parameters.

In contrast to the rescue of mutant standard the sensitivity of the detection of single bp mutations depends on the frequency of polymerase errors during the replication of a particular bp. Only polymerase errors originating from wt-sequences will interfere since errors in already mutated sequences will give rise to double mutations which are not detected with oligonucleotide probes containing a single altered base. Therefore, the final polymerase error frequencies will depend on the completeness of the removal of wt-sequences by restriction and our protocol employs several steps of restriction before and during amplification. We used conditions for the amplification reaction which were expected to yield relatively low Taq-polymerase errors (10) but retained high amplification efficiency, i.e. $\mathrm{Mg}^{2+}$ concentration of $6.7 \mathrm{mM}$, a total concentrations of dNTPs of 4 $\mathrm{mM}$ but a relatively high $\mathrm{pH}$ of $8.2\left(70^{\circ} \mathrm{C}\right)$. The data in Figure 4 attests to the large differences in Taq-polymerase errors depending on the type of $b p$ and the sequence. The replication of G.C bp produced more errors then the replication of A.T bp and transversions were considerably more frequent than transitions. Sequence dependence is indicated by the fact that the $\mathrm{C} \rightarrow \mathrm{G}$ transversion (AGGT) was more frequent than the $\mathrm{G} \rightarrow \mathrm{C}$ transversion $(\mathrm{ACCT})$ and the $\mathrm{C} \rightarrow \mathrm{A}$ transversion $(\mathrm{AG} \underline{\mathrm{AT}}$ ) more frequent than the $\mathrm{G} \rightarrow \mathrm{T}$ transversion (ATCT). Comparison of the three panels in Figure 4 indicates that the fraction of plaques with Taq-polymerase errors did not change significantly when the initial number of wt-copies was increased from $10^{8}$ to $10^{9}$. Under the latter conditions a single copy of mutant standard resulted in $0.3 \%$ mutant standard plaques. We estimate that at best RFLP/PCR analysis at PvuII-site $1727-1732$ is capable of rescueing $1-5$ copies of a single bp mutation from $10^{9}$ copies of c-Ha-ras 1 for mutations with low Taq-polymerase error frequencies, e.g. for $\mathrm{A} \rightarrow \mathrm{C}(\underline{\mathrm{CGCT}}), \mathrm{T} \rightarrow \mathrm{G}(\mathrm{AGCG}), \mathrm{A} \rightarrow \mathrm{T}$

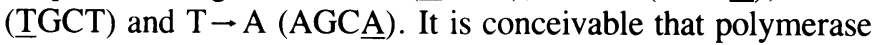
errors can be further reduced by modifying the amplification conditions $(10,11)$ and consequently that the sensitivity of our RFLP/PCR protocol can be increased.

We have further assessed the sensitivity of the RFLP/PCR protocol for the rescue of a single bp mutation in the MspI-site 1695-1698 of exon 1 of c-Ha-ras1. Unlike the rescue of a doubly mutated standard such as pSP64-ras PvuIISt the capacity to rescue a single bp mutation is limited by backgrounds caused by polymerase errors. The experimental conditions were analogous to the PvuII-site 1727-1732 with the exception that nested 'clonable' left-side amplimer was used for the final 10 PCR cycles. The chosen mutant results from a $\mathrm{G} \rightarrow \mathrm{T}$ transversion at bp 1698 which represents the middle bp of codon 12. Mutations in this ras-codon are frequently detected in the DNA from human tumor tissues (1) and the particular $\mathrm{G} \rightarrow \mathrm{T}$ transversion studied in the present work had been first detected in the EJ human bladder carcinoma line (8). Our results show that 100 copies of a ras 1 fragment containing a mutated MspI-site 1695-1698 with a T-residue in position 1698 could be readily rescued from $10^{8}$ copies of wt ras1 DNA. As expected from the analysis of the PvuII-site 1727-1732 under similar experimental conditions the $\mathrm{G} \rightarrow \mathrm{T}$ transversion at bp 1698 represents a relatively frequent Taq-polymerase error. The fraction of plaques containing the T1698 mutation was $12 \%$ for the sample composed initially of only wt DNA. This value is comparable to $11 \%$ for the frequency of Taq-polymerase induced $\mathrm{G} \rightarrow \mathrm{T}$ transversions at bp 1729 in the PvuII-site $1727-1732$ for the sample containing initially only 1 copy of PvulI mutant standard but $10^{9}$ copies of wt ras 1 DNA.

The predominance of transversions involving G.C bp in our experiments disagrees with published work in which A.T. $\rightarrow$ G.C 
transitions were reported to be the most frequent Taq-polymerase errors $(10,11,12,13)$. Differences in the amplification conditions may be responsible for these discrepancies; e.g. high ratios of concentrations of $\mathrm{Mg}^{2+} /$ total dNTPs in several published reports relative to a ratio of 1.7 in the present work; the use of relatively high concentrations of DMSO in our work in contrast to previous authors etc.. It should be stressed that our data does not allow it to calculate absolute error-frequencies for Taq-polymerase because the amount of residual, unrestricted wt-sequence in the amplification mixture cannot be assessed by the RFLP/PCR protocol.

In conclusion, the RFLP/PCR protocol described here allows the analysis of point mutations (bp-changes, small deletions and insertions) in any gene of known sequence without the need to select mutated cells on the basis of an altered phenotype. The method is highly sensitive and relatively simple but limited to mutations which result in the elimination of a restriction site. The experimental design of the RFLP/PCR approach to genotypic mutation analysis has been discussed previously $(14,15)$.

\section{ACKNOWLEDGEMENTS}

This work was supported by the Swiss National Science Foundation and the Swiss Association of Cigarette Manufacturers and the Association for International Cancer Research.

\section{REFERENCES}

1. Bos, J.L. (1988) Mutat. Res. 195, 255-271.

2. Baker, S.J., Fearon, E.R., Nigro, J.M., Hamilton, S.R., Presinger, A.C., Jessup, J.M., van Tuinen, P., Ledbetter, D.H., Barker, D.F., Nakamura, Y., White, R. and Vogelstein, B. (1989) Science 244, 217-221.

3. Nigro, J.M., Barker, S.J., Preisinger, A.C., Jessup, J.M., Hostetter, R., Cleary, K., Bigner, S., Davidson, N., Baylin, S., Devilee, P., Glover, T., Collins, F., Weston, A., Modali, R., Harris C., and Vogelstein, B. (1989) Nature 342, 705-708.

4. Takahashi, T., Nau, M., Chiba, I., Birrer, M., Rosenberg, R., Vinocour, M., Levitt, M., Pass, H., Gazdar, A. and Minna, J. (1989) Science 246, 491-494.

5. See in 'Mutation and the Environment. Part C: Somatic and Heritable Mutation, Adduction and Epidemiology' (1989) (ed.) Mendelsohn, M. and Albertini, R., Wiley-Liss.

6. Rossiter, B. and Caskey, C.T. (1990) J. Biol. Chem. 265, 12753-12756.

7. Parada, L., Tobin C., Shih, C. and Weinberg, R. (1982) Nature 297, 474-478.

8. Capon, D., Chen, E., Levinson, A. Seeburg, P. and Goeddel, D. (1983) Nature 302, 33-37.

9. Salmons, B., Groner B., Friis, R., Muell, D., and Jaggi , R. (1986) Gene $45,215-220$.

10. Eckert, K., and Kunkel, T. (1990) Nucl. Acid. Res. 18, 3739-3743.

11. Keohavong, P. and Thilly, W. (1988) Proc. Natl.Acad. Sci. 86, 820-823.

12. Saiki, R., Gelfand, D., Stoffel, S., Scharf, S., Higuchi, R., Horn, G. Mullis, K. and Erlich, H. (1988) Science 239, 487-491.

13. Tindall, K. and Kundel, T. (1988) Biochemistry 27, 6008-6013.

14. Zijlstra, J., Felley-Bosco, E., Amstad, P. and Cerutti, P. (1990) in 'Mutagens and Carcinogens in the Diet' pp. 187-200 (eds. M. Pariza et al), WileyLiss, New York.

15. Parry, J., Shamsher, M., and Skibinski, D., (1990) Mutagenesis 5, 209-212. 